\title{
NOTES ON PRACTICAL METHODS FOR THE STUDY OF MARINE DIATOMS
}

\author{
By T. J. HART, D.Sc. \\ National Institute of Oceanography, Wormley, Surrey
}

In the study of marine diatoms examination of fresh material (or of wet mounts in some suitable preservative such as formalin-sea water) is essential, in addition to 'permanent' mounts of 'cleaned' frustules, because the violent cleaning process destroys many of the more delicate forms (e.g. the genus Guinardia). Conversely, it is not possible to see the fine details of skeletal structure, upon which the taxonomy of so many diatoms is based, while the organic contents of the cells are still present.

Scatter-mounts are preferred to arranged slides because the examination of large numbers of individuals is essential if the wide range of variation within species of this group is to be justly appreciated (cf. Hendey, I938, I95I). Further, they help one to appreciate the relative abundance of species within the sample, provided that wet mounts have previously been examined.

The 'cleaning'-removal of the organic contents of the frustules-may be carried out by direct incineration in a platinum crucible, but some form of wet combustion is usually found better and more convenient. The successive treatments with strong mineral acids and powerful bleaching agents that this involves can be carried out satisfactorily as described by Hendey (1938, I95I) if there is ample material available. Frequently, however, in marine biological work, it is necessary to use very small quantities; for example, the gut contents of a few small invertebrates, or the epiphytes from the shell of a single large barnacle.

It is possible to apply the same schedule of successive washings and treatment with acids that Hendey recommends, to smaller amounts of material, if one's facilities include the use of a small centrifuge and a fume cupboard. The reagents can safely be added (in the very small quantities needed) to material in a $12 \mathrm{ml}$. centrifuge tube directly with a pipette provided the mouth of the tube is kept pointing away from the face of the operator, towards the far side of the fume cupboard. Much time is saved by concentrating the material centrifugally between each stage instead of waiting for it to settle before decanting off the unwanted fluids. The elimination of sulphuric acid is especially facilitated by the small quantity (ca. $4 \mathrm{ml}$.) of reagent needed. One can dilute it by cautiously pipetting water into it in the tube, allowing it to 'kick' slightly and boil momentarily until the tube is gradually filled. This eliminates most of the possibility of trouble from spurting acid when, after bringing the material down again with the 
centrifuge, the acid is finally poured off. With the speeding up of the process that use of the centrifuge permits, extra stages, such as treatment with a fat-solvent or extra washing with distilled water can easily be interpolated at appropriate points in the schedule.

Centrifuge tubes of Pyrex glass, scrupulously cleaned, should be used; and it is important to make sure that their ends are adequately cushioned against direct contact with the bottoms of the buckets. It is essential to use one newly drawn or very thoroughly cleaned pipette for all stages in the manipulation of each separate sample.

By these means good cleaned samples of marine diatom frustules ready for mounting have been obtained from material as diverse as plankton samples, epiphytes, scrapings from the skin-film of whales and diatomaceous bottom muds; working with very small quantities of material when necessary.

The material, once cleaned and washed, can conveniently be stored in very small vials, labelled, corked and waxed, in either distilled water or alcohol. Alcohol is preferred because it prevents the growths that may take place if the material is stored in water for a long time.

Before mounting dehydration is necessary and this can be completed by direct heating and use of a desiccator filled with fresh silica gel. Several cleaned cover-glasses are placed on black paper in a small petri dish, one large drop of the material, agitated until the diatom frustules cause a faint milkiness of the fluid, is pipetted on to each, the dish covered and heated at just above $100^{\circ} \mathrm{C}$ for a time, then removed to the desiccator. The slips are now ready for mounting by placing a small drop of the chosen medium near the centre of each, inverting it on to a cleaned slide and proceeding with the appropriate after-treatment (hardening, usually by gentle heat, and perhaps ringing).

There remains the choice of a suitable mountant, and here we are faced with the old problem resulting from the fact that diatom-silex has a refractive index quoted as around $\mathrm{I} \cdot 40-\mathrm{I} \cdot 42$, so near to that of the best general mountants (e.g. Euparal I.46 and Canada balsam I.52) that the index of visibility of frustules mounted in them is too low. A mountant of much higher refractive index is needed.

Much patient experiment with mixtures of sulphur, phosphorus and alkaloids with other substances, usually resinous, and with fluids such as monobromonaphthalene, has been carried out in the past by such workers as Morris (1885) and Bellido (1897, 1927). The latter's work was translated into English (1927) and is extensively quoted by Gray (I953). Bellido's methods resulted in perhaps the finest diatom mounts ever made, rivalling the famous arranged slides of Müller. They consisted essentially of mounting in monobromonaphthalene sealed in hardened shellac cells. The technique is laborious and time-consuming, however, demanding a manipulative skill that can only be acquired through months of practice. The shellac also needs special purification. 
In the meantime 'Styrax', and 'Hyrax', a proprietary resin of high refractive index, became popular with several workers. The use of Styrax is described in the introductory chapters of Hustedt's monograph (I930). We have had some good results with these media; but Styrax is difficult to control in the drying-off stages, when bubbles are frequently drawn in under the cover-glass, and it is inclined to give rather a dark ground colour. Moreover, Hustedt (1952) has since found Hyrax inadequate for some forms.

Ghazzawi(I933) revived an old method that dates back to the time of Morris's experiments, a solid but thermoplastic medium of good keeping qualities, obtained by grinding antimony tribromide with the alkaloid piperine. We found that this demanded very careful control of heating, difficult to apply in practice, and that the post-war price of piperine was prohibitive.

Jelly (I930), working on sections of cellulose nitrate film for Kodak Ltd., got good results by melting Canada balsam with alphabromonaphthalene ( $15 \mathrm{~g}$ to Io $\mathrm{ml}$.) on the water-bath. He suggested that this mixture, which gave him a refractive index of $N_{D}=\mathrm{I} \cdot 59 \mathrm{I}$, might also be useful with diatomaceae and ice crystals. I have had moderate success with it (Hart, I935), but found that some mounts set poorly and tended to develop globules unless the proportions were modified, using a smaller quantity of a bromonaphthalene in balsam already made up with xylene. Some of the mounts thus obtained have lasted well for over 20 years, but the gain in refractive index is too small to give the best results with delicate frustules.

Latterly, the introduction of synthetic resins has led to the introduction of various mountants mostly known only under proprietary names, at least two of which were evolved expressly for the use of diatomists, by authors who published directions for their small-scale synthesis. These are 'Naphrax' (Flemming, 1943) and 'Pleurax' (Hanna, 1949). Pleurax was used extensively by Dr Cupp in the work leading up to her monograph on the marine diatoms of the Pacific coast of North America (Cupp, I943), which should be a strong recommendation. A sample of Naphrax obtained commercially was very dark-coloured, which detracted from its otherwise excellent optical qualities. We hope to repeat the syntheses described by Fleming and Hanna eventually, in order to test Naphrax and Pleurax against the media described below.

Another proprietary mountant tried has been 'Clearax'-water white with a refractive index stated to be $\mathrm{I} \cdot 66$ when set. It gave good results, but other media seemed better.

For a long time I had failed to find Hanna's description of the small-scale synthesis of his Pleurax, and it was this that led me to experiment on lines suggested partly by Jelly's work, and partly by that of Kirkpatrick \& Lendrum (I939). The latter developed a most useful cheap substitute for balsam (DPX, also 'DePex') for bacteriological and histological mounting by dissolving distrene-8o, one of the polystyrenes already available commercially, in xylol, with the addition of a small proportion of tritolyl phosphate as plasticizer. 
This medium is especially good for preserving the colour of some delicate stains that tend to fade in balsam; its refractive index, however, is but little higher than that of ordinary Canada balsam in xylol.

It was found that the synthetic resin could be dissolved in $a$-bromonaphthalene, and that the resultant syrup was miscible with xylene. Further, it could also be dissolved in $a$-iodonaphthalene, introducing a darker colour but an even higher refractive index. Finally, a useful medium for diatom mounts was achieved by mixing the three solutions obtained by dissolving distrene- 80 to saturation in xylene, $a$-bromonaphthalene and $a$-iodonaphthalene, with the aid of gentle heat, in the proportions: two parts xylene solution, two parts $a$-bromonaphthalene solution, one part $a$-iodonaphthalene solution.

The mounts should be dried off at temperatures not greatly exceeding $100^{\circ} \mathrm{C}$ for about $\mathrm{I} \mathrm{h}$, and baked again similarly on the following day. If they are heated too strongly or too long immediately after mounting, bubble trouble may result. The mixed medium seems stable in an ordinary balsambottle. It may be thickened slightly by evaporating off some of the xylene, or thinned by adding more xylene as necessary.

The mounts seem good optically and have lasted for several months without being ringed. Ringing with gold-size may increase their keeping properties. Two out of some fifty have shown development of minute globules, such as Morris complained of in fluid mounts made with monobromonaphthalene alone, and which he avoided by incorporating a minute proportion of salicilate of chinoline in the mountant. With these polystyrene mixtures, it is thought that the defect was due rather to inadequate dessication before mounting, than to the quality of the naphthalene derivatives, which are obtainable in a much more pure state than in Morris's day.

The heavy halogen naphthalene derivatives have also been tried again mixed with Canada balsam in high proportions, as suggested by Jelly. This gave quite useful mounts but several developed globules in time, and all showed much more background colour than those made from the synthetic resin mixture. Other promising experiments have been made using venetian turpentine (more soluble than Canada balsam in ethylalcohol) as the resinous base, with the same optically effective liquids. It was hoped that by this means material stored in alcohol might be mounted more readily, since complete dessication would not be such a strict necessity. Some good mounts resulted, but dark background colour was again found to be a considerable disadvantage.

Only time can show the keeping qualities of the successful mixture of distrene-80 with xylene and the heavy halogen derivatives of naphthalene. Our next step must be to complete the small-scale syntheses of 'Naphrax' and Pleurax as so generously described by Drs Fleming and Hanna and see how they compare with our mountant. At worst the distrene-80 mixture 
provides a first class examination medium easy to prepare and far superior to temporary fluid mounts, even though they may not prove fully 'permanent'.

Throughout the later experiments Prof. Gray's source reference book has been a great help. I should like to thank the Director of the Plymouth Laboratory of the M.B.A., where the work was begun years ago; and also Dr Cox, chemist on the N.I.O. staff, for advice and encouragement.

\section{REFERENCES}

Bellido, Don Ernesto Caballero, i897. In An. Soc. esp. Hist. nat. [Not seen, a subsequent Spanish ed. appeared 1926, and an English translation quoted below.]

- 1927. The technique of mounting diatom and other type slides. [Communicated by Dr C. Tierney from trans. by Mr Frederick Adams.] F. R. micr. Soc., Vol. 47, pp. 9-28.

Cupp, E. E., 1943. Marine plankton diatoms of the West Coast of North America. Bull. Scrifps Instn Oceanogr., Vol. 5, pp. I-238.

FLEMING, WILliAM D., I943. A synthetic mounting medium of high refractive index. F. R. micr. Soc., Vol. 63, pp. 34-7.

Ghazzawi, F. M., I933. The littoral diatoms of Liverpool and Port Erin shores. f. mar. biol. Ass. U.K., Vol. 19, pp. 165-76.

Gray, Peter, 1953. The Microtomists' Formulary and Guide. London: Constable and Co.

HanNa, G. D., 1949. A synthetic resin which has unusual properties. F. R. micr. Soc., Vol. 69, pp. 25-8.

HaRT, T. J. 1935. On the diatoms of the skin-film of whales, and their possible bearing on problems of whale movements. 'Discovery' Rep., Vol. Io, pp. 247-82.

HENDEY, N. INGRAM, 1938. An efficient technique for cleaning diatoms. F. $R$. micr. Soc., Vol. 58, pp. 49-52.

- I95I. Littoral diatoms of Chichester Harbour with special reference to fouling. F. R. micr. Soc., Vol. 7I, pp. I-86.

HustedT, FR., 1930. Die Kieselalgen Deutschlands, Österreichs und der Schweiz, Rabenhorst's Kryptogamenflora, Bd. 7, Teil I, Leipzig.

- 1952. Diatomeen aus der lebensgemeinshaft des Buckelwals (Megaptera nodosa Bonn). Arch. Hydrobiol., Bd. 46, pp. 286-98.

Jelly, Edwin E., 1930. Mounting medium for film sections. Nature, Lond., Vol. I25, p. 276.

KirkPATRICK, J. \& LendRUM, A. C., I939. A mounting medium for microscopical preparations, giving good preservation of colour. F. Path. Bact., Vol. 49, p. 593.

MORRIS, WILlIAM, I885. Notes on experiments in mounting the Amphiplura pellucida in media having a higher refractive index than Canada balsam. F. roy. Soc., N.S.W., Vol. 19, pp. 121-33. 